CZASOPISMO INŻYNIERII LĄDOWEJ, ŚRODOWISKA I ARCHITEKTURY JOURNAL OF CIVIL ENGINEERING, ENVIRONMENT AND ARCHITECTURE JCEEA, t. XXXIII, z. 63 (2/I/16), kwiecień-czerwiec 2016, s. 299-306

\author{
Piotr REZKA ${ }^{1}$ \\ Wojciech BALCERZAK ${ }^{2}$ \\ Justyna KWAŚNY ${ }^{3}$
}

\title{
SZTUCZNE SUBSTANCJE SŁODZĄCE - WYSTĘPOWANIE W ŚRODOWISKU
}

\begin{abstract}
W pracy przedstawiono zagadnienie występowania sztucznych substancji słodzących w ściekach oraz ich obecności w środowisku wodnym. Ze względu na zastosowanie w produkcji żywności i napojów o zmniejszonej wartości kalorycznej, związki te pojawiają się w ściekach w coraz większych ilościach. Najczęściej stosowanymi substytutami cukru jest acesulfam K, aspartam, cyklaminian sodu, sacharyna i sukraloza. Każda z tych substancji jest kilkadziesiąt razy bardziej słodka niż standardowy cukier (sacharoza), jednakże praktycznie nie podnoszą one wartości kalorycznej produktu. Dokonano przeglądu literatury, skupiając się na zawartościach rozpatrywanych substancji w ściekach surowych i oczyszczonych. Wykazano, że skuteczność eliminacji tych związków ze ścieków jest niewystarczająca i na skutek tego dochodzi do zanieczyszczenia środowiska wodnego. Przedstawiono w tabeli potwierdzone doniesienia dotyczące obecności tych związków w rzekach, jeziorach i wodach podziemnych. W przypadku gdy w wodzie ujmowanej przez stacje uzdatniania wody obecne są wyżej wymienione związki, w szczególności acesulfam i sukraloza, istnieje ryzyko przedostania się ich do wody przeznaczonej do spożycia, co znalazło potwierdzenie w literaturze. Mimo dostępnych wyników badań nie wykazujących wpływu na ekosystem i zdrowie człowieka, konieczne wydaje się przeprowadzenie badań nad wpływem długotrwałego narażenia organizmów wodnych i organizmu człowieka na działanie sztucznych substytutów cukru.
\end{abstract}

Słowa kluczowe: jakość wody, ścieki, wody powierzchniowe, wody podziemne, woda do picia

\section{Wprowadzenie}

Kwestia obecności związków organicznych w ściekach i środowisku wodnym stała się jednym z głównych tematów poruszanych w publikacjach nauko-

\footnotetext{
${ }^{1}$ Autor do korespondencji/corresponding author: Piotr Rezka, Politechnika Krakowska, ul. Warszawska 24, 31-155 Kraków, rezkapiotr@gmail.com

2 Wojciech Balcerzak, Politechnika Krakowska, ul. Warszawska 24, 31-155 Kraków, wb@vistula.wis.pk.edu.pl

3 Justyna Kwaśny, Politechnika Krakowska, ul. Warszawska 24, 31-155 Kraków, kwasny.justyna@gmail.com
} 
wych na całym świecie. Największe kontrowersje budzą doniesienia o występowaniu farmaceutyków i składników produktów do pielęgnacji ciała w środowisku wodnym i glebach; mniejszą uwagę zwracają natomiast publikacje dotyczące substancji słodzących. Jest to najprawdopodobniej spowodowane nastawieniem ludzi do danej grupy związków. Obecnie żywność i napoje zawierające substytuty cukru są w pełni świadomie wybierane przez konsumentów. Częste doniesienia o szkodliwym wpływie cukru (sacharozy) na organizm i utrzymanie smukłej sylwetki powodują wzrost zainteresowania artykułami o niższej wartości kalorycznej i niższej zawartości cukru. Z tego właśnie względu można zaobserwować rosnący wybór produktów w wersji „light” z substytutami cukru, w zdecydowanej większości sztucznymi. Zastosowanie np. acesulfamu K, który jest 200-krotnie bardziej słodki od sacharozy, pozwala z jednej strony na obniżenie kosztów produkcji, z drugiej natomiast na znaczne obniżenie kaloryczności produktu, przez co dany produkt staje się bardziej atrakcyjny dla osób walczących z nadwagą lub dbających o linię.

Należy jednak także pamiętać, że syntetyczne substancje słodzące (AS - artificial sweeteners) również mogą mieć negatywny wpływ na organizm człowieka. Najbardziej krytykowanym substytutem cukru jest niewątpliwie aspartam, budzący kontrowersje od kilkudziesięciu lat. Obecnie jest on uważany za bezpieczny dla organizmu, jednakże pogląd ten jest często podważany ze względu na wyniki badań sugerujące, że aspartam jest neurotoksyną i może wpływać na rozwój nowotworów mózgu. Coraz popularniejszy obecnie substytut, jakim jest sukraloza pośrednio wpływa negatywnie na nabłonek jelita (negatywne działanie wykazują metabolity sukralozy). Mimo wątpliwości co do szkodliwości lub jej braku na organizm człowieka, większość substancji słodzących jest uznawana za bezpieczne, dlatego można spodziewać się ich obecności w artykułach spożywczych i ich konsumpcji. W Tablicy 1 zestawiono podstawowe informacje dotyczące rozpatrywanych w pracy syntetycznych substancji słodzących.

\section{Występowanie substancji słodzących}

\section{1. Ścieki miejskie}

Powszechne przeświadczenie o braku przeciwwskazań do spożywania sztucznych substytutów cukru przekłada się wprost na większe zużycie w produkcji żywności i napojów. Coraz częściej spotykaną praktyką jest dodawanie substancji słodzących do preparatów farmaceutycznych w celu poprawy nieprzyjemnego smaku produktu.

Oznacza to, że głównym źródłem AS w ściekach doprowadzanych do miejskich oczyszczalni ścieków są ścieki bytowo-gospodarcze. Analizy ścieków surowych wykonane pod kątem obecności AS wykazują stężenia rzędu do kilkudziesięciu lub kilkuset mikrogramów w litrze ścieku: ACE 0,187-75 $\mu \mathrm{g} / \mathrm{l}$, ASP do 2,26 $\mu \mathrm{g} / \mathrm{l}$, CYC 0,3-250 $\mu \mathrm{g} / \mathrm{l}$, SAC 0,5-135 $\mu \mathrm{g} / \mathrm{l}$, SUC 0,1-4,72 $\mu \mathrm{g} / \mathrm{l}$ [17]; ACE 
Tablica 1. Charakterystyka rozpatrywanych substancji słodzących, na podstawie [11,21-25]

Table 1. Characteristics of considered artificial sweeteners, based on [11,21-25]

\begin{tabular}{|c|c|c|c|}
\hline Nazwa & Wzór sumaryczny & Wzór strukturalny & Numer CAS \\
\hline $\begin{array}{l}\text { Acesulfam K } \\
\text { (ACE) }\end{array}$ & $\mathrm{C}_{4} \mathrm{H}_{4} \mathrm{KNO}_{4} \mathrm{~S}$ & & $55589-62-3$ \\
\hline $\begin{array}{l}\text { Aspartam } \\
\text { (ASP) }\end{array}$ & $\mathrm{C}_{14} \mathrm{H}_{18} \mathrm{~N}_{2} \mathrm{O}_{5}$ & & 22839-47-0 \\
\hline $\begin{array}{l}\text { Cyklaminian sodu } \\
\text { (CYC) }\end{array}$ & $\mathrm{C}_{6} \mathrm{H}_{12} \mathrm{NSO}_{3} \mathrm{Na}$ & & 139-05-9 \\
\hline $\begin{array}{l}\text { Sacharyna } \\
\text { (SAC) }\end{array}$ & $\mathrm{C}_{7} \mathrm{H}_{5} \mathrm{NO}_{3} \mathrm{~S}$ & & $81-07-2$ \\
\hline $\begin{array}{l}\text { Sukraloza } \\
\text { (SUC) }\end{array}$ & $\mathrm{C}_{12} \mathrm{H}_{19} \mathrm{Cl}_{3} \mathrm{O}_{8}$ & & $56038-13-2$ \\
\hline
\end{tabular}

do $111 \mu \mathrm{g} / \mathrm{l}$ (średnio $42 \mu \mathrm{g} / \mathrm{l}$ ) [9]; ACE 49-149 $\mu \mathrm{g} / \mathrm{l}$, ASP do 0,07 $\mu \mathrm{g} / \mathrm{l}, \mathrm{CYC}$ do $3,7 \mu \mathrm{g} / \mathrm{l}, \mathrm{SAC} 7,4-155 \mu \mathrm{g} / \mathrm{l}$, SUC 12-60 $\mu \mathrm{g} / \mathrm{l}$ [2]. Zauważalna jest różnica w stężeniach aspartamu i cyklaminianu w różnych miastach, co potwierdza, że nie można z góry założyć profilu stężeń substytutów cukru obecnych w ściekach.

Specyfika ścieków z gospodarstw domowych i ich zmienny skład utrudnia prowadzenie procesów oczyszczania ścieków w sposób efektywny z punktu widzenia eliminacji AS, co znajduje potwierdzenie w wynikach analiz ścieków oczyszczonych. Zakres stężeń AS obecnych w ściekach odprowadzanych do rzek jest bardzo zróżnicowany: ACE 30,7-32,7 $\mu \mathrm{g} / \mathrm{l}$, CYC 17,2-20 $\mu \mathrm{g} / \mathrm{l}, \mathrm{SAC}$ 6,4-9,1 $\mu \mathrm{g} / \mathrm{l}, \mathrm{SUC}$ 15,4-18,1 $\mu \mathrm{g} / \mathrm{l}$ [11]; ACE 9,3-61,2 $\mu \mathrm{g} / \mathrm{l}$, ASP do 11,5 $\mu \mathrm{g} / \mathrm{l}$, CYC do 19,2 $\mu \mathrm{g} / \mathrm{l}, \mathrm{SAC}$ do 16,2 $\mu \mathrm{g} / \mathrm{l}$ i SUC 0,68-7,6 $\mu \mathrm{g} / 1$ [3]; ACE do $54 \mu \mathrm{g} / \mathrm{l}$, CYC do 16,6 $\mu \mathrm{g} / \mathrm{l}, \mathrm{SAC}$ do 55,1 $\mu \mathrm{g} / \mathrm{l}$ [19]; SAC $5 \mu \mathrm{g} / \mathrm{l}$, SUC 0,8-1,8 $\mu \mathrm{g} / \mathrm{l}$ [5]; SUC średnio $27 \mu \mathrm{g} / 1$ [10]; SUC 0,4-119 $\mu \mathrm{g} / 1$ [16]; ACE 3,6 $\mu \mathrm{g} / \mathrm{l}$, SUC 1,25 $\mu \mathrm{g} / \mathrm{l}$ [1]. Przytoczone wyniki potwierdzają, że substancje słodzące nie są degradowane i eliminowane w procesach oczyszczania ścieków w sposób efektywny, czego skutkiem jest przenikanie tych związków do środowiska. 


\subsection{Wody naturalne}

Nieefektywne oczyszczanie ścieków jest głównym powodem obecności AS w środowisku wodnym. W przypadku nieefektywnego oczyszczenia ścieków, substytuty cukru mogą być odprowadzane do rzek - odbiorników ścieków oczyszczonych. Stężenia AS występujących w wodach powierzchniowych i podziemnych wraz ze źródłami literaturowymi umieszczone zostały w Tabeli 2.

Tabela 2. Stężenia w $\mu \mathrm{g} / 1$ (min-max lub średnia) wybranych AS

Table 2. Concentrations in $\mu \mathrm{g} / \mathrm{l}$ ( $\min -\max$ or mean) of selected AS

\begin{tabular}{|c|c|c|}
\hline Nazwa & Rzeki, jeziora & Wody podziemne \\
\hline $\begin{array}{l}\text { Acesulfam K } \\
\text { (ACE) }\end{array}$ & $\begin{array}{r}0,12-1,62^{[2]} \\
0,036-7,34^{[3]} \\
0,4-53,7^{[11]} \\
0,03-9,6^{[12]} \\
0,02-0,38^{[14]} \\
0,005-0,35^{[17]} \\
0,05-2,01^{[19]}\end{array}$ & $\begin{array}{r}0,005-0,095^{[17]} \\
0,026-33,6^{[18]} \\
0,05-2,87^{[19]} \\
0,012-1,53^{[20]}\end{array}$ \\
\hline $\begin{array}{l}\text { Aspartam } \\
\text { (ASP) }\end{array}$ & $0,01-0,03^{\lfloor 2]}$ & $0,005-0,013^{[3]}$ \\
\hline $\begin{array}{l}\text { Cyklaminian sodu } \\
\text { (CYC) }\end{array}$ & $\begin{array}{r}0,02-0,08^{[2]} \\
0,036-1,96^{[3]} \\
0,8-15,7^{[11]} \\
0,016-0,12^{[12]} \\
0,005-0,27^{[14]} \\
0,028-1,4^{[17]} \\
0,05-0,245^{[19]}\end{array}$ & $\begin{array}{r}0,007-0,021^{[3]} \\
0,005-0,087^{[17]} \\
0,023-0,98^{[18]} \\
0,05-1,2^{[19]}\end{array}$ \\
\hline $\begin{array}{l}\text { Sacharyna } \\
\text { (SAC) }\end{array}$ & $\begin{array}{r}0,023-0,31^{[3]} \\
0,2-19,7^{[11]} \\
0,025-0,49^{[12]} \\
0,02-0,26^{[14]} \\
0,04-0,81^{[17]}\end{array}$ & $\begin{array}{r}0,005-0,015^{[3]} \\
0,01-0,21^{[17]} \\
0,035-2^{[18]}\end{array}$ \\
\hline $\begin{array}{l}\text { Sukraloza } \\
\text { (SUC) }\end{array}$ & $\begin{array}{r}0,04-3,6^{[2]} \\
0,044-0,95^{[3]} \\
0,07-3,47^{[4]} \\
0,8-1,8^{[5]} \\
0,12-10^{[10]} \\
0,4-5,3^{[11]} \\
0,2-1,0^{[12]} \\
0,01-0,22^{[14]} \\
0,001-1,9^{[16]}\end{array}$ & $\begin{array}{r}0,8-2,4^{[5]} \\
5-24^{[18]} \\
0,065-0,54^{[20]}\end{array}$ \\
\hline
\end{tabular}

\subsection{Woda przeznaczona do spożycia}

Woda z rzeki lub woda podziemna ujmowana przez stacje uzdatniania wody może zawierać substancje słodzące. W takiej sytuacji oczekiwane jest skuteczne oczyszczanie wody z zanieczyszczeń organicznych, by woda przeznaczo- 
na do spożycia nie zawierała substancji, których konsumenci mogą sobie nie życzyć. Popularność produktów zawierających AS nie oznacza, że każdy odbiorca wody do picia ma zamiar wprowadzać je do swojego organizmu. Jest to szczególnie ważne w świetle najnowszych badań, które wykazują wpływ AS na rozwijanie się nietolerancji glukozy poprzez zmianę mikroflory w jelitach [15].

Analizy przeprowadzone w Szwajcarii wykazały obecność ACE w wodzie przeznaczonej do picia w ilości do $69 \mathrm{ng} / \mathrm{l}$ [3]. W Chinach wykryto już kilka substytutów cukru: ACE 0,58-0,68 $\mu \mathrm{g} / \mathrm{l}, \mathrm{CYC} 0,03-0,04 \mu \mathrm{g} / \mathrm{l}, \mathrm{SAC}$ 0,07-0,1 $\mu \mathrm{g} / \mathrm{l}$ oraz SUC 0,09-0,12 $\mu \mathrm{g} / 1$ [6]. Natomiast w Stanach Zjednoczonych analizy wykazały obecność sukralozy w bardzo wysokich, jak na uzdatnioną wodę stężeniach w przedziale $0,05-2,4 \mu \mathrm{g} / 1$ [7]. Powyższe wyniki dowodzą, że substancje słodzące nie są całkowicie usuwane $w$ procesach uzdatniania wody i mogą, w szczególności acesulfam i sukraloza, docierać do odbiorców wody przeznaczonej do picia.

\section{Substancje słodzące jako wskaźnik zanieczyszczenia}

Nieefektywna eliminacja substancji słodzących ze ścieków nie oznacza, że nie można wykorzystać faktu powszechnego występowania tych związków w środowisku wodnym. Substancje o charakterze antropogenicznym, czyli pochodzenia ludzkiego i nie występujące naturalnie w przyrodzie można potraktować jako swego rodzaju wskaźnik zasięgu i rozmiaru zanieczyszczenia środowiska przez ludzi. Szwajcarscy badacze potraktowali acesulfam jako wskaźnik populacji w badanym regionie, w celu określenia rozmiaru analizowanego przez nich potencjalnego zanieczyszczenia antropogenicznego [8]. Sacharyna, jako substytut cukru będący w użyciu już około 50 lat, może posłużyć jako wskaźnik ewentualnego skażenia środowiska przez odcieki ze starych składowisk odpadów [13].

\section{Wnioski}

Dokonany w artykule przegląd literatury i wyniki analiz ukazują skalę problemu, jakim jest występowanie syntetycznych substytutów cukru w środowisku wodnym. Mimo niskich, w porównaniu do spożywanych ilości substancji słodzących wraz z pożywieniem, stężeń tych związków, należy krytycznie podchodzić do kwestii ich niedostatecznej degradacji i eliminacji przede wszystkim w procesach oczyszczania ścieków. Efektywne oczyszczenie ścieków z AS pozwoliłoby uniknąć zanieczyszczaniu ogółu środowiska naturalnego. Duża mobilność AS i rozpuszczalność w wodzie sprzyjają zanieczyszczeniu nie tylko wód powierzchniowych, ale także wód podziemnych i akumulowaniu się w roślinach.

Jednakże najbardziej krytycznie należy podchodzić do obecności AS w wodzie do picia. Zwolennicy sztucznych substancji słodzących mogą nie mieć nic przeciwko ich obecności, jednakże innego zdania są ich przeciwnicy. $Z$ tego 
względu należy poszukiwać efektywnych metod oczyszczania wody z opisywanych substancji. Niewątpliwie potrzebne są szerokie, kompleksowe i wiarygodne badania dotyczące długotrwałej ekspozycji organizmów wodnych i organizmu człowieka na substytuty cukru, aby jednoznacznie stwierdzić szkodliwość lub brak szkodliwości tych związków.

\section{Literatura}

[1] Alidina, M., Hoppe-Jones, C., Yoon, M., Hamadeh, A.F., Li, D., Drewes, J.E., The occurrence of emerging trace organic chemicals in wastewater effluents in Saudi Arabia, Science of the Total Environment, nr 478, 2014, s. 152-162.

[2] Arbelaez, P., Borrull, F., Pocurull, E., Marce, R.M., Determination of high-intensity sweeteners in river water and wastewater by solid-phase extraction and liquid chromatography-tandem mass spectrometry, Journal of Chromatography A, nr 1393, 2015, s. 106-114.

[3] Berset, J.-D., Ochsenbein, N., Stability considerations of aspartame in the direct analysis of artificial sweeteners in water samples using high-performance liquid chromatography-tandem mass spectrometry (HPLC-MS/MS), Chemosphere, $\mathrm{nr} 88$, 2012, s. 563-569.

[4] Dong, B., Kahl, A., Cheng, L., Vo, H., Ruehl, S., Zhang, T., Snyder, S., Saez, A.E., Quanrud, D., Arnold, R.G., Fate of trace organics in a wastewater effluent dependent stream, Science of the Total Environment, nr 518-519, 2015, s. 479-490.

[5] Ferrer, I., Thurman, M., Analysis of sucralose and other sweeteners in water and beverage samples by liquid chromatography/time-of-flight mass spectrometry, Journal of Chromatography A, nr 1217, 2010, s. 4127-4134.

[6] Gan, Z., Sun, H., Feng, B., Wang, R., Zhang, Y., Occurrence of seven artificial sweeteners in the aquatic environment and precipitation of Tianjin, China, Water Research, nr 47, 2013, s. 4928-4937.

[7] Mawhinney, D.B., Young, R.B., Vanderford, B.J., Borch, T., Snyder, S.A., Artifcial sweetener sucralose in U.S. drinking water systems, Environmental Science Technology, nr 45, 2011, s. 8716-8722.

[8] Muller, C.E., Gerecke, A.C., Alder, A.C., Scheringer, M., Hungerbuhler, K., Identification of perfluoroalkyl acid sources in Swiss surface waters with the help of the artificial sweetener acesulfame, Environmental Pollution, nr 159, 2011, s. 1419-1426.

[9] Nodler, K., Hillebrand, O., Idzik, K., Strathmann, M., Schiperski, F., Zirlewagen, J., Licha, T., A comparative study with selected $\beta$-blockers and the persistent anthropogenic wastewater indicators carbamazepine and acesulfame, Water Research, $\mathrm{nr} 47$, 2013, s. 6650-6659.

[10] Oppenheimer, J., Eaton, A., Badruzzaman, M., Haghani, A.W., Jacangelo, J.G., Occurrence and suitability of sucralose as an indicator compund of wastewater loading to surface waters in urbanized regions, Water Research, nr 45, 2011, s. 4019-4027.

[11] Ordonez, E.Y., Quintana, J.B., Rodil, R., Cela, R., Determination of artificial sweeteners in water samples by solid-phase extraction and liquid chromatographytandem mass spectrometry, Journal of Chromatography A, nr 1256, 2012, s. $197-205$. 
[12] Perkola, N., Sainio, P., Quantification of four artificial sweeteners in Finnish surface waters with isotope-dilution mass spectrometry, Environmental Pollution, nr 184, 2014, s. 391-396.

[13] Roy, J.W., Van Stempvoort, D.R., Bickerton, G., Artificial sweeteners as potential tracers of municipal landifll leachate, Environmental Pollution, nr 184, 2014, s. 89-93.

[14] Sang, Z., Jiang, Y., Tsoi, Y.-K., Leung, K.S-Y., Evaluating the environmental impact of artificial sweeteners: A study of their distributions, photodegradation and toxicities, Water Research, nr 52, 2014, s. 260-274.

[15] Suez, J., Korem, T., Zeevi, D., Zilberman-Schapira, G., Thaiss, C.A., Maza, O., Israeli, D., Zmora, N., Gilad, S., Weinberger, A., Kuperman, Y., Harmelin, A., Kolodkin-Gal, I., Shapiro, H., Halpern, Z., Segal, E., Elinav, E., Artificial sweeteners induce glucose intolerance by altering the gut microbiota, Nature, nr 514, 2014, s. $181-186$.

[16] Tollefsen, K.E., Nizzetto, L., Huggett, D.B., Presence, fate and effects of the intense sweetener sucralose in the aquatic environment, Science of the Total Environment, $\mathrm{nr}$ 438, 2012, s. 510-516.

[17] Tran, N.H., Hu, J., Ong, S.L., Simultaneous determination of PPCPs, EDCs and artificial sweeteners in environmental water samples using a single-step SPE coupled with HPLC-MS/MS and isotope dilution, Talanta, nr 113, 2013, s. 82-92.

[18] Van Stempvoort, D.R., Roy, J.W., Brown, S.J., Bickerton, G., Artificial sweeteners as potential tracers in groundwater in urban environments, Journal of Hydrology, nr 401, 2011, s. 126-133.

[19] Wolf, L., Zwiener, C., Zemann, M., Tracking artificial sweeteners and pharmaceuticals introduced into urban groundwater by leaking sewer networks, Science of the Total Environment, nr 430, 2012, s. 8-19.

[20] Wu, M., Qian, Y., Boyd, J.M., Hrudey, S.E., Le, C.X., Li, X.-F., Direct large volume injection ultra-high performance liquid chromatography-tandem mass spectrometry determination of artificial sweeteners sucralose and acesulfame in well water, Journal of Chromatography A, nr 1359, 2014, s. 156-161.

[21] www.chemspider.com/Chemical-Structure.55940.html (Acesulfam K) - dostęp 31.05.2015.

[22] www.chemspider.com/Chemical-Structure.118630.html (Aspartam) - dostęp 31.05.2015.

[23] www.chemspider.com/Chemical-Structure.8421.html (Cyklaminian sodu) - dostęp 31.05.2015.

[24] www.chemspider.com/Chemical-Structure.4959.html (Sacharyna) - dostęp 31.05.2015.

[25] www.chemspider.com/Chemical-Structure.64561.html (Sukraloza) - dostęp 31.05.2015.

\section{ARTIFICIAL SWEETENERS - OCCURRENCE IN THE ENVIRONMENT}

\section{S u m m a r y}

The paper presents the problem of the occurrence of artificial sweeteners in wastewater and their presence in the aquatic environment. Due to the use in the manufacture of reduced-calorie food and beverages, these compounds are present in the effluent in increasing numbers. Most popular artificial sugar substitutes are acesulfame $\mathrm{K}$, aspartame, sodium cyclamate, saccharin and 
sucralose. Each of these substances is tens of times more sweet than conventional sugar (sucrose), but they do not increase the calorific value of the product. A review of the literature, focusing on the concentrations of described substances in raw sewage and treated wastewater was made. It has been shown that the effectiveness of the sweeteners elimination from wastewater is insufficient, resulting in contamination of the aquatic environment. Confirmed reports of the presence of these compounds in rivers, lakes and groundwater are shown in table. If artificial sweeteners, particularly acesulfame and sucralose, are present in raw water grasped by water treatment plants, there is a risk of those compounds being released along with water intended for human consumption, which has been confirmed in the literature. Although the available studies do not show any negative impact on the ecosystem and human health, it seems necessary to carry out studies on the effects of long-term exposure of human and aquatic organisms to artificial sugar substitutes.

Keywords: water quality, wastewater, surface water, groundwater, drinking water

Przestano do redakcji: 11.12.2015 r.

Przyjęto do druku: 1.03.2016 r.

DOI: $10.7862 /$ rb.2016.131 